\title{
Heterogeneity of histopathological presentation of pilocytic astrocytoma - diagnostic pitfalls. A review
}

\author{
Ewa Matyja ${ }^{1}$, Wiesława Grajkowska ${ }^{2}$, Katarzyna Stępieñ ${ }^{1}$, Ewa Naganska ${ }^{1}$ \\ ${ }^{1}$ Department of Experimental and Clinical Neuropathology, Mossakowski Medical Research Centre, Polish Academy of Sciences, \\ 2Department of Pathology, The Children's Memorial Health Institute, Warsaw, Poland
}

\begin{abstract}
Pilocytic astrocytomas (PAs) are the most frequent primary astroglial tumours affecting children and adolescents. They occur sporadically or in association with a genetically determined syndrome - neurofibromatosis type 1. Classic PA usually manifests as a well-circumscribed, often cystic, slowly growing tumour, which corresponds to WHO grade I. The majority of pilocytic tumours arise along the neuraxis, predominantly in the cerebellum. They are associated with favourable long-term outcome or spontaneous regression, even after incomplete resection. However, the behaviour and prognosis might also be related to tumour histology and location. Pilomyxoid astrocytoma (PMA) represents a variant of classical PA with more invasive growth and increased risk of recurrences and dissemination. Typically, PAs exhibit distinct histology with biphasic architecture of loose, microcystic and compact, fibrillary areas. However, some tumours arise in an uncommon location and display heterogeneous histopathological appearance. The morphological pattern of PA can mimic some other glial neoplasms, including oligodendroglioma, pleomorphic xanthoastrocytoma, ependymoma or diffuse astrocytoma. Not infrequently, the advanced degenerative changes, including vascular fibrosis, and recent and old haemorrhages, may mimic vascular pathology. Sometimes, the neoplastic piloid tissue can resemble reactive gliosis, related to long-standing non-neoplastic lesions. Not infrequently, PA exhibits histological features typical for anaplasia, including necrosis, mitoses and glomeruloid vascular proliferation that can suggest a diffuse high-grade glioma. However, even those PAs that lack distinct histological features of anaplasia can behave unpredictably, in a more aggressive manner, with leptomeningeal spreading.

Genetic alterations resulting in aberrant signalling of the mitogen-activated protein kinase (MAPK) pathway have been considered to underlie the development of PAs. The most commonly identified KIAA1549-BRAF fusion is important for appropriate tumour molecular diagnosis.

In this paper we summarize the clinicopathological presentation of PAs, with emphasis on their heterogeneous morphology, based on our own experience in the field of surgical neuropathology and the literature data. Diagnosis of pilocytic tumours requires careful analysis of clinical, histopathological and molecular features to avoid misinterpretation of these benign neoplastic lesions.
\end{abstract}

Key words: pilocytic astrocytoma, pilomyxoid variant, low-grade glioma, heterogeneous morphology. 


\section{Introduction}

Pilocytic astrocytoma (PA) is a well-circumscribed, well-differentiated, slowly growing tumour, corresponding to WHO grade I. It is included in the group of "other astrocytic tumours" in the revised $4^{\text {th }}$ edition of the current 2016 WHO Classification of Tumours of the Central Nervous System [25]. Typically, PAs exhibit a non-diffuse pattern of cell growth, although they may locally infiltrate leptomeninges or adjacent brain tissue.

The vast majority of cases are associated with benign clinical behaviour and a favourable long-term outcome, particularly those of cerebellar location and complete surgical resection [27-29,60]. However, some tumours, despite their benign histology, may behave more aggressively. The pilomyxoid variant of pilocytic astrocytoma (PMA) is suggested to represent a subtype with more invasive growth and increased risk of recurrences $[49,50]$. Occasionally, the classic PA may exhibit the distinct histological features of anaplasia such as necrosis, mitoses and vascular proliferation $[10,25,31,53,82,90,101]$. Some other factors, including partial resection, brainstem location and adult age, are also associated with a worse prognosis [27].

Generally, PA is characterized by distinct clinicopathological features, but not infrequently it manifests heterogeneous appearance, including older age of patients, uncommon location, lack of classical biphasic pattern, presence of nuclear atypia, mitoses, necrosis and vascular glomeruloid changes. In such cases the accurate diagnosis may be challenging [60]. Moreover, the biological behaviour of pilocytic astrocytomas, independently of their clinical course and morphology, is not always predictable.

This report evaluates our own experience in the field of surgical neuropathology of PA and reviews the literature. The correct diagnosis of PA has important therapeutic and prognostic implications; thus the careful analysis of clinical, histopathological and molecular features is required to avoid misinterpretation in differential diagnosis.

\section{Incidence}

Pilocytic astrocytomas occur most commonly in paediatric and young adults in the age group 0-19 years [71], constituting $10 \%$ of cerebral and $85 \%$ of cerebellar tumours. They are often associated with neurofibromatosis type 1 (NF1), especially those cas- es developing in the optic/chiasmatic region. The latter account for at least $40 \%$ of cases associated with NF1 [58]. Pilocytic astrocytomas are rarely encountered in patients older than 50 years $[20,37,59]$. The oldest patients with pathologically confirmed PA were an 86-year-old woman [63] and an 85-year-old man with post mortem diagnosis of PA in the brainstem [20].

\section{Localization}

Pilocytic astrocytomas may arise along the entire neuraxis. They affect preferentially the cerebellum but may arise in the optic pathway, hypothalamus, brainstem and spinal cord [27,60]. Less commonly they are located in the basal ganglia and cerebral hemispheres. In the paediatric age group, PAs develop preferentially in hemispheres of the cerebellum, followed by the brain stem and spinal cord. Occasionally, PA may develop in the neurohypophysis/ suprasellar region [79] and pineal gland [8]. Brain stem tumours usually appear as a compact dorsal exophytic mass lesion [5]. Exceptionally, paediatric PA may occur as a cerebellopontine angle mass, well separated from the brain stem $[65,92]$.

In adult patients, the majority of PAs are located supratentorially $[14,18]$, less commonly in the cerebellum [96,100], cervicomedullary region [103] or other parts of the spinal cord $[37,74,86]$. Occasionally, PA in adult patients are associated with haemorrhages and manifest as spontaneous intracranial haemorrhage $[57,59]$.

\section{Clinical and radiological findings}

The clinical presentation of PA depends on tumour location. The neuroimaging findings of PAs, including conventional and advanced magnetic resonance imaging (MRI) sequences, depend on the tumour size, location and tendency to infiltrate the surrounding structures [22]. Typically, PA occurs on computed tomography (CT) and MRI as a well-demarcated, contrast-enhancing lesion that reveals characteristic solid and micro- or macrocystic components [98]. The cyst with an enhancing mural nodule is a classic radiological feature. The solid part usually shows homogeneous contrast enhancement. On MRI, the tumour appears as hypo- or isointense lesion on T1-weighted images and hyperintense on T2-weighted images [55]. Tumour calcifications occur only occasionally. 
In some PA cases, the neuroradiological images may be unusual, including small cyst formation, heterogeneously or irregularly enhancing tumour nodules and internal haemorrhages [68]. Uncommonly, the radiological features of PAs can resemble highgrade gliomas.

\section{Histopathology}

The borders of PAs are usually well-defined, but sometimes the neoplastic infiltration of adjacent brain tissue can be seen (Fig. 1A). Tumours of cortical location may demonstrate invasion of the leptomeninges with extensive desmoplastic reaction (Fig. 1B).

Typically, PA exhibits a well-recognizable biphasic pattern with a mixture of loose microcystic and more compact regions (Fig. 1C, D). Such distinct biphasic architecture is particularly evident in tumours of cerebellar location. Numerous small cysts of different size and shape, filled with eosinophilic, myxoid material, could be seen (Fig. 1E, F) The microcystic, loose-textured areas contain stellate astroglial cells resembling protoplasmic astrocytes and globular, mulberry-shaped, eosinophilic granular bodies (EGBs) or hyaline globules (Fig. 2A). Eosinophilic granular bodies are formed by aggregates of tiny granular bodies (Fig. 2B) situated within the astrocytic processes. They exhibit periodic acidSchiff, $\alpha_{1}$-antichymotrypsin and $\alpha_{1}$-antitrypsin reactivity. The compact parts of the tumour are mostly composed of bipolar piloid cells with delicate "hairlike" processes. Some more solid areas may contain a large amount of eosinophilic structures corresponding to EGBs and/or hyaline droplets (Fig. 2C) or Rosenthal fibres (Fig. 2D). The latter appear as eosinophilic, hyaline, corkscrew-like structures (Fig. 2E), which accumulate within the tumour cell processes. Ultrastructurally, they are electron-dense granular masses surrounded by intermediate glial filaments. Rosenthal fibres are composed of $\alpha$-B-crystallin and do not express glial fibrillary acidic protein (GFAP) positivity or exhibit only peripheral immunostaining. Some regions are composed entirely of a large number of Rosenthal fibres. It is well known that both EGB and Rosenthal fibres are not specific for PA; nevertheless, they can serve as a suitable marker of slow-growing lesions. Eosinophilic granular bodies are often present in other non-diffuse glial and glio-neuronal tumours, including ganglioglioma and pleomorphic xanthoastrocytoma. Rosenthal fibres are also a frequent component of chronic reactive piloid gliosis associated with other neoplastic brain lesions, i.e. craniopharyngioma, cerebellar haemangioblastoma or spinal ependymoma. Similar looking gliosis might also be encountered in the pineal cyst and various non-neoplastic lesions associated with the reactive response of astroglia. It is noteworthy that both EGBs and Rosenthal fibres are not required for the diagnosis of PA.

Immunohistochemically, the neoplastic cells of PAs show strong GFAP immunoreactivity (Fig. 2F), S-100 protein and OLIG2 positivity.

The classic biphasic architecture was evident in the majority of PAs cases. However, some tumours are composed predominantly or even entirely of one growth pattern. They display either microcystic or solid appearance, with or without EGBs or Rosenthal fibres. Such monomorphic morphology can be confusing and challenging for neuropathologists.

Not infrequently, PAs contain areas of oligodendroglioma-like pattern (Fig. 3A) with a honeycomb picture formed by uniform cells with a clear perinuclear halo (Fig. 3B). Such morphology mimicking oligodendroglioma predominates in the histological picture of some pilocytic astrocytomas [95].

Pilocytic astrocytomas usually show signs of degenerative changes, typical for slowly growing, long-standing lesions. They include not only presence of Rosenthal fibres and EGBs, but also focal increase of cellularity with nuclear hyperchromasia (Fig. 3C) and cellular pleomorphism (Fig. 3D). Large, pleomorphic, often multinucleated cells reflect advanced degenerative changes which have no prognostic significance (Fig. 3E). Some cells, corresponding to the cells known as "pennies-on-a-plate", exhibit multiple nuclei arranged circumferentially in the cytoplasm (Fig. 3F). Occasionally, thin or psammomatous calcifications can be found (Fig. 3G, H). It is a frequent finding in optic nerve, hypothalamic/thalamic and superficially located cerebral tumours. Densely calcified PAS of the brainstem [15] and unique cases of intraventricular PA with densely calcified tissue and psammomatous bodies were reported [47,52].

Some tumours exhibit a focal angiocentric pattern with ependymoma-like perivascular arrangement of neoplastic cells (Fig. 4A). Such a pattern might be seen in oligodendroglioma-like areas (Fig. 4B). Occasionally, the neoplastic cells are arranged in ribbons or palisades (Fig. 4C). The fibrillary pattern of neoplastic tissue, resembling diffuse astrocytomas, 

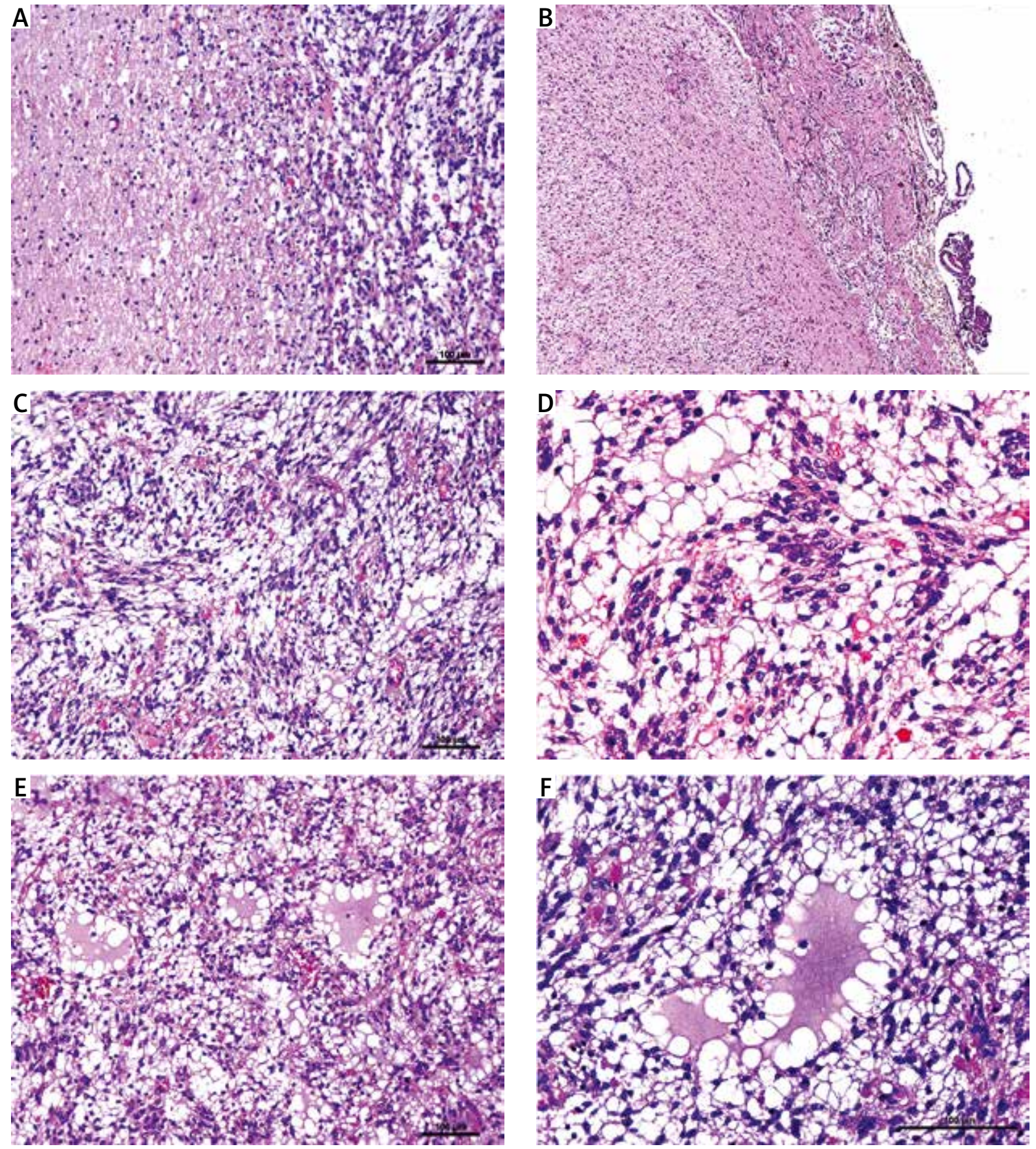

Fig. 1. Morphology of pilocytic astrocytoma. A) Well demarcation of the tumour from the surrounding tissue with only limited infiltration along the border zone. B) Superficially located tumour with leptomeningeal tumour growth. C) Classic biphasic pattern with microcystic tissue. D) Biphasic architecture with loose, spongy component and compact, fibrillary elements. E) Small cysts of different size and shape within loose, microcystic background. F) Microcyst filled with eosinophilic, myxoid material. 

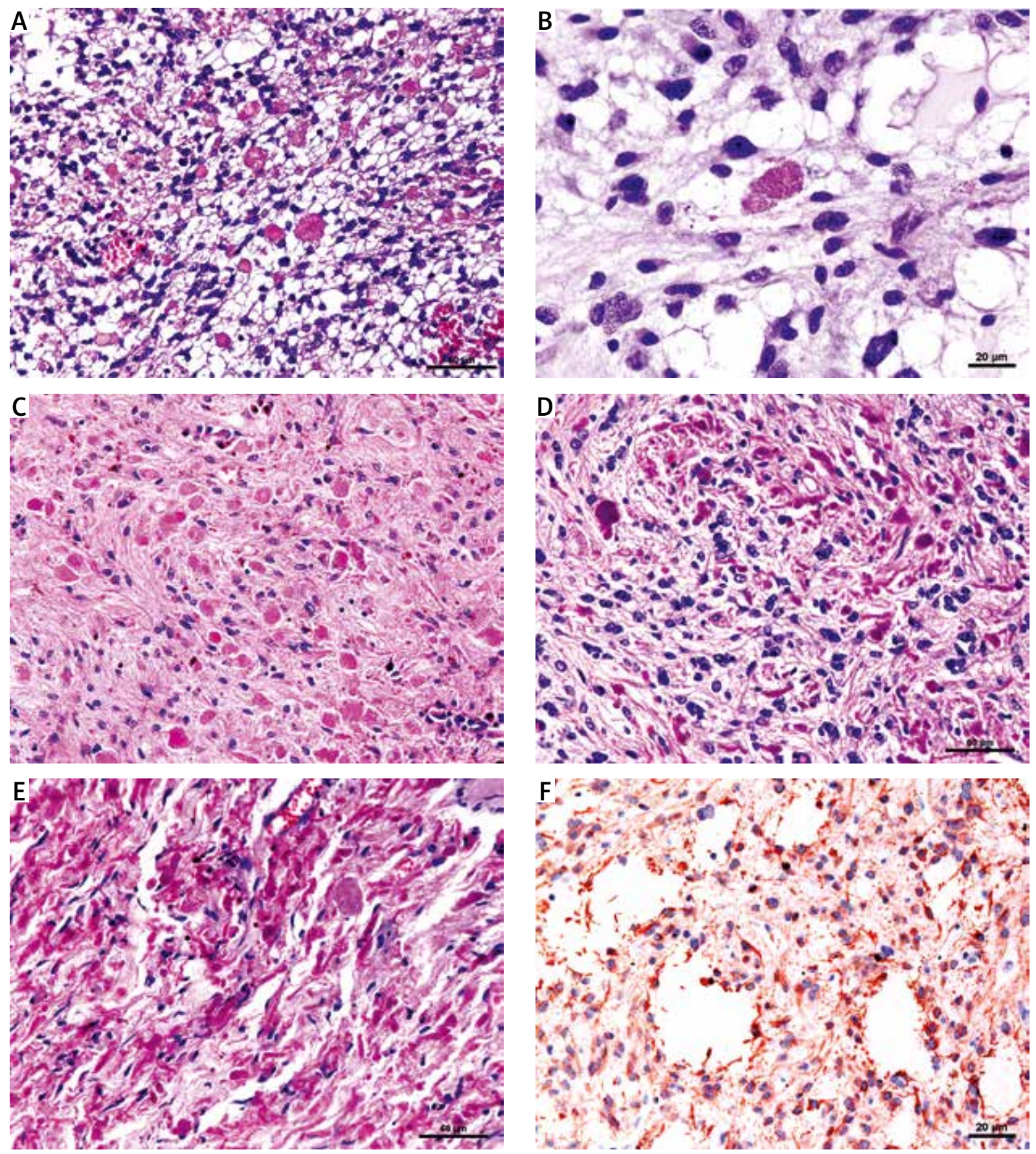

Fig. 2. Typical histopathological features of pilocytic astrocytoma. A) Microcystic, loose-textured areas containing eosinophilic granular bodies (EGBs) and hyaline droplets. B) Eosinophilic granular bodies formed by the aggregates of tiny granular bodies. C) Eosinophilic, compact region with numerous eosinophilic structures corresponding to EGBs and/or hyaline droplets. D) More solid component with increased cellularity and focal accumulation of Rosenthal fibres. E) Compact, fibrillary tumour tissue with numerous Rosenthal fibres. F) Glial fibrillary acidic protein expression in neoplastic cells. 

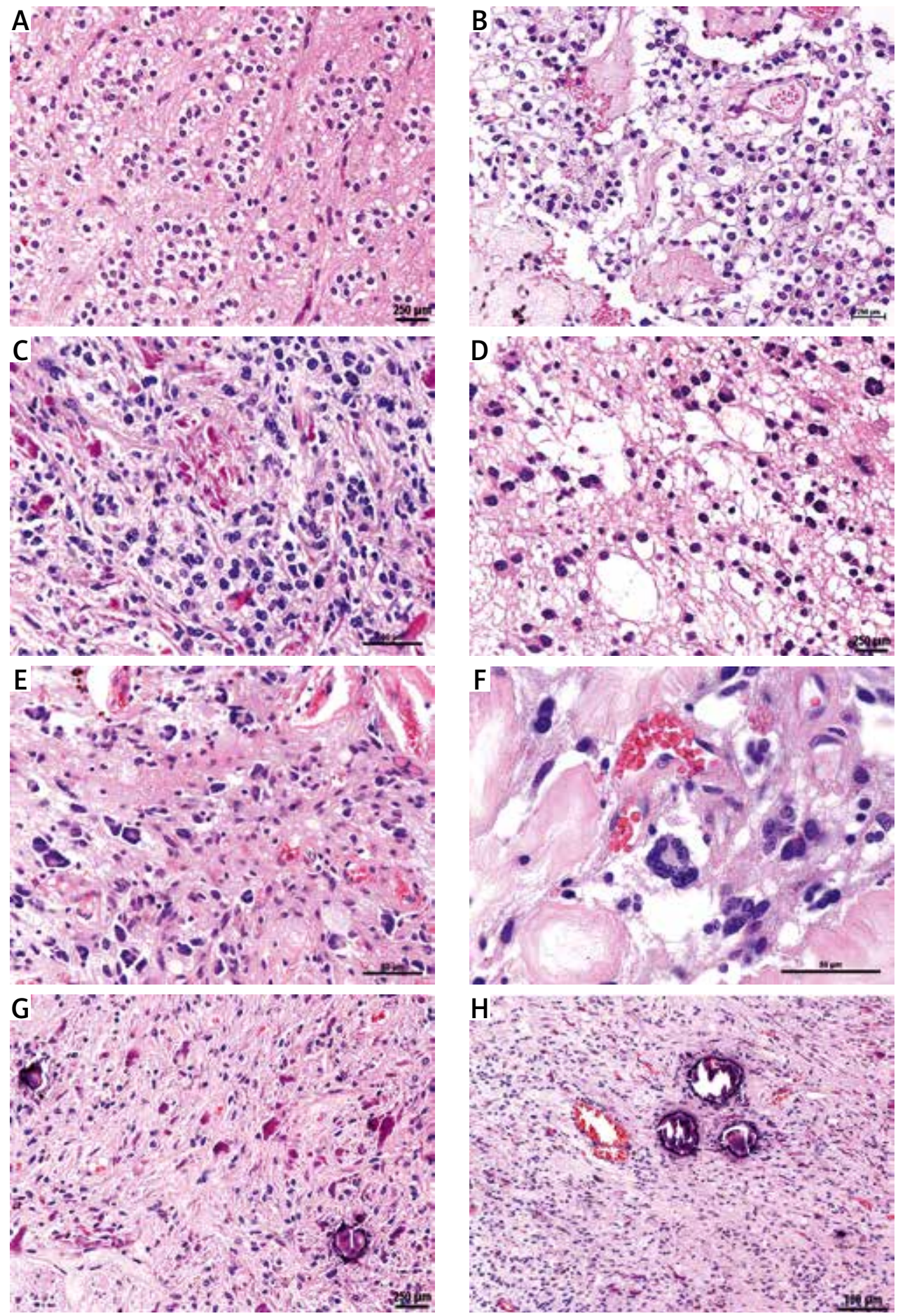

Fig. 3. Heterogeneous pattern of pilocytic astrocytoma. A) Pilocytic astrocytoma with predominant oligodendroglioma-like architecture. B) Oligodendroglioma-like pattern with uniform cells exhibiting clear perinuclear halo. C) Compact tissue with increased cellularity, nuclear hyperchromasia and atypia. Rosenthal fibres are present. D) Spongy tissue with pleomorphic cells displaying degenerative nuclear atypia. E) Large, pleomorphic, often multinucleated cells. F) Cell with multiple nuclei arranged circumferentially in the cytoplasm, corresponding to "pennies-on-a-plate". G) Compact, fibrillary tissue with Rosenthal fibres and tiny calcifications. H) Fibrillary tissue with psammomatous calcifications. 

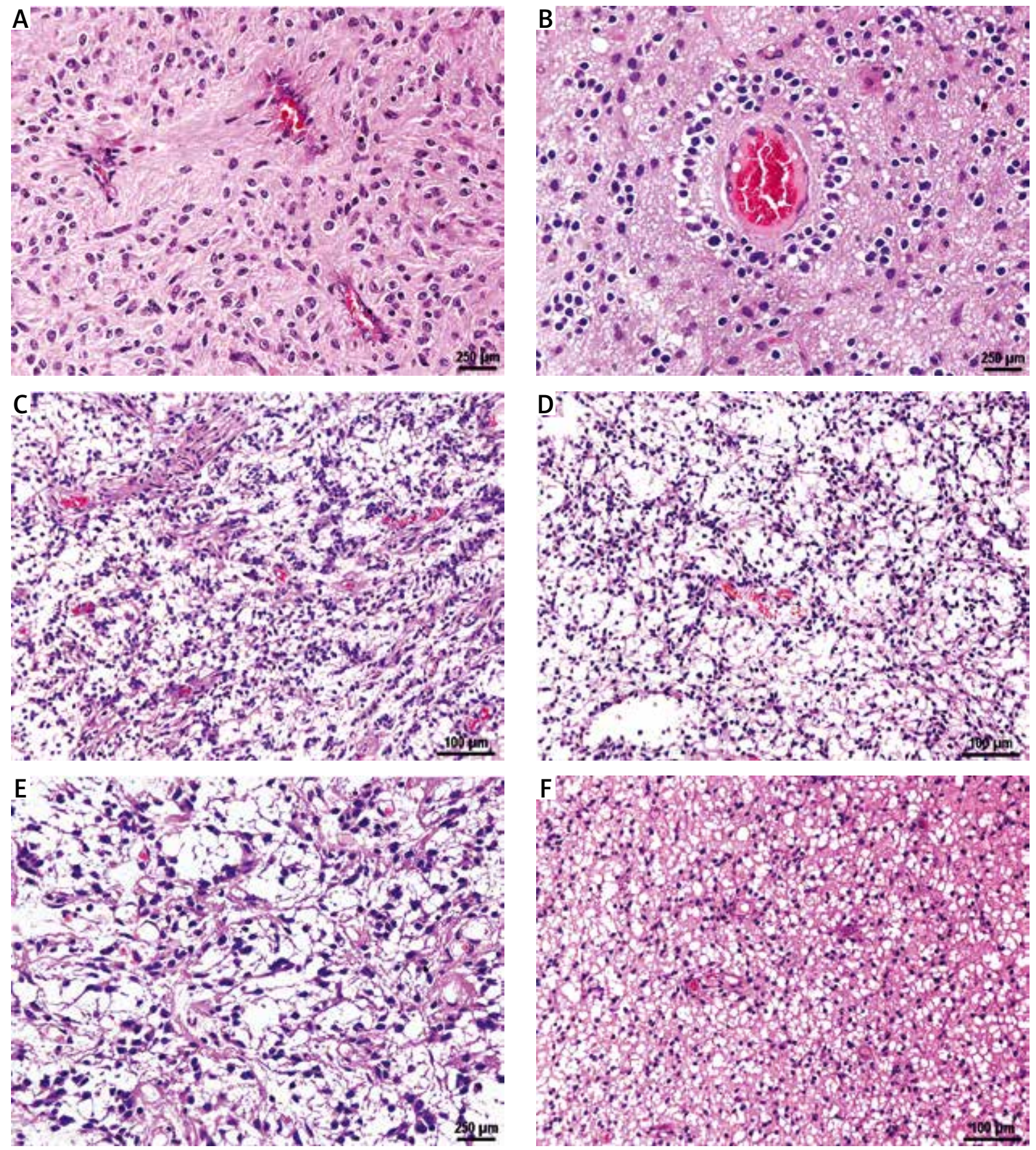

Fig. 4. Patterns of pilocytic astrocytoma mimicking other glial neoplasms. A) Ependymoma-like perivascular arrangement of neoplastic cells. B) Angiocentric arrangement of neoplastic cells resembling oligodendroglioma cells. C) Ribbons or palisaded arrangement of neoplastic cells. D) Tumour tissue resembling diffuse astrocytomas. E) Neoplastic cells with cytological atypia, nuclear hyperchromasia and fine fibrillary background. F) Slightly spongy tissue composed of uniform neoplastic fibrillary astrocytic cells mimicking diffuse astrocytoma. 
is not unique (Fig. 4D). Sometimes, the fine fibrillary background is accompanied by cytological atypia, uneven cell distribution and nuclear hyperchromasia (Fig. 4E). Slightly spongy tissue composed of uniform neoplastic fibrillary astrocytic cells may mimic diffuse astrocytoma (Fig. 4F).

Pilocytic astrocytomas often appear as highly vascular tumours. The blood vessels may exhibit advanced fibrosis and/or hyalinization of vascular walls (Fig. 5A). Sometimes, the closely packed, sclerotic, largely hyalinized vessels can resemble vascular malformations, i.e. cavernous angioma (Fig. 5B). The neoplastic tissue may be scant and dispersed between conglomerates of thickened, hyalinized blood vessels (Fig. 5C, D), thus more mimicking reactive piloid gliosis around a lesion of vascular pathology than true neoplastic proliferation. In such cases the misleading diagnosis of cavernous angioma might be established. The advanced angiomatous proliferation might resemble capillary haemangio$\mathrm{ma}$, and the diagnosis of so-called angioglioma has been proposed [62]. In chronic lesions, the hemosiderin deposits of old haemorrhages and calcifications are often seen. An unusual case of pigmented cerebellar PA, presenting with posttraumatic haemorrhage in a 38-year-old man, has been described [93]. Advanced vascular abnormalities are sometimes associated with infarct-like necrosis. Other vascular changes are associated with proliferation of microvessels. Such microvascular proliferation often appears as linear arrays (Fig. 5E), especially within the cyst wall of the tumour. Typical glomeruloid changes of the vessels with hyperplasia of endothelial cells might suggest the diagnosis of high-grade gliomas (Fig. 5F). However, the microvascular proliferation of glomeruloid type in PAs should not be considered as a sign of anaplasia. Nevertheless, the careful analysis of clinicopathological findings supported by the molecular profile is required to distinguish PA from diffusely infiltrating gliomas.

Additionally, nuclear atypia, mitosis, necrosis, vascular proliferation and spread into leptomeninges and/or surrounding tissue, mimicking highgrade diffuse gliomas, may be rarely observed. Only occasionally, tumours with brisk mitotic activity, necrosis and marked nuclear pleomorphism have been diagnosed as anaplastic PA [82]. It has been documented that anaplastic/malignant transformation of PA occurred most often in association with previous ionizing radiation [75] or surgery alone [88], whereas spontaneous malignant transformation was unique $[10,72,90]$. The majority of anaplastic cases have been described in adults $[10,101]$. Nevertheless, PAs with anaplastic features do not always exhibit a clear correlation between morphology and tumour behaviour. Only some cases of malignant PA have been documented to progress extremely rapidly [53].

Occasionally, the pre-existing neurons may be entrapped in the neoplastic tissue. Such lesions with residual neuronal elements should be distinguished from true gangliogliomas with a piloid astroglial component.

\section{Histological variant}

The pilomyxoid variant (PMA) of pilocytic astrocytoma exhibits different histological features and behaves more aggressively than PA [50]. It demonstrates piloid cells within a markedly loose, myxoid background that lacks Rosenthal fibres or EGB, characteristic for classic PAs (Fig. 6A). Bipolar tumour cells are arranged radially around blood vessels, thus resembling the angiocentric arrangement or perivascular pseudorosettes seen in ependymomas (Fig. 6B). Some tumours revealed intermediate features of both PMA and classic PA.

Pilomyxoid astrocytoma usually develops in the hypothalamic region, optic chiasm and third ventricle in infants and young children, less commonly in the thalamus, posterior fossa, brain stem, temporal lobe and spinal cord [49]. It has been suggested that PMAs ought to be included in the differential diagnoses of the lesions invading the sella turcica [3].

The clinical behaviour of PMAs is unpredictable. Usually, they behave more aggressively than conventional PAs. Pilomyxoid astrocytoma was classified as a tumour of grade II in the 2007 WHO classification of tumours of the central nervous system [17], but in the current revised $4^{\text {th }}$ edition of the WHO 2016 classification, the determination of its grade of malignancy is not recommended.

\section{Immunohistochemistry}

Pilocytic astrocytomas express markers from the astrocytic lineage. They show strong GFAP immunostaining, S-100 protein and OLIG2 positivity. The Rosenthal fibres are strongly positive for $\alpha-B$ crystallin and exhibit only peripheral GFAP staining. Synaptophysin immunoexpression could be found 

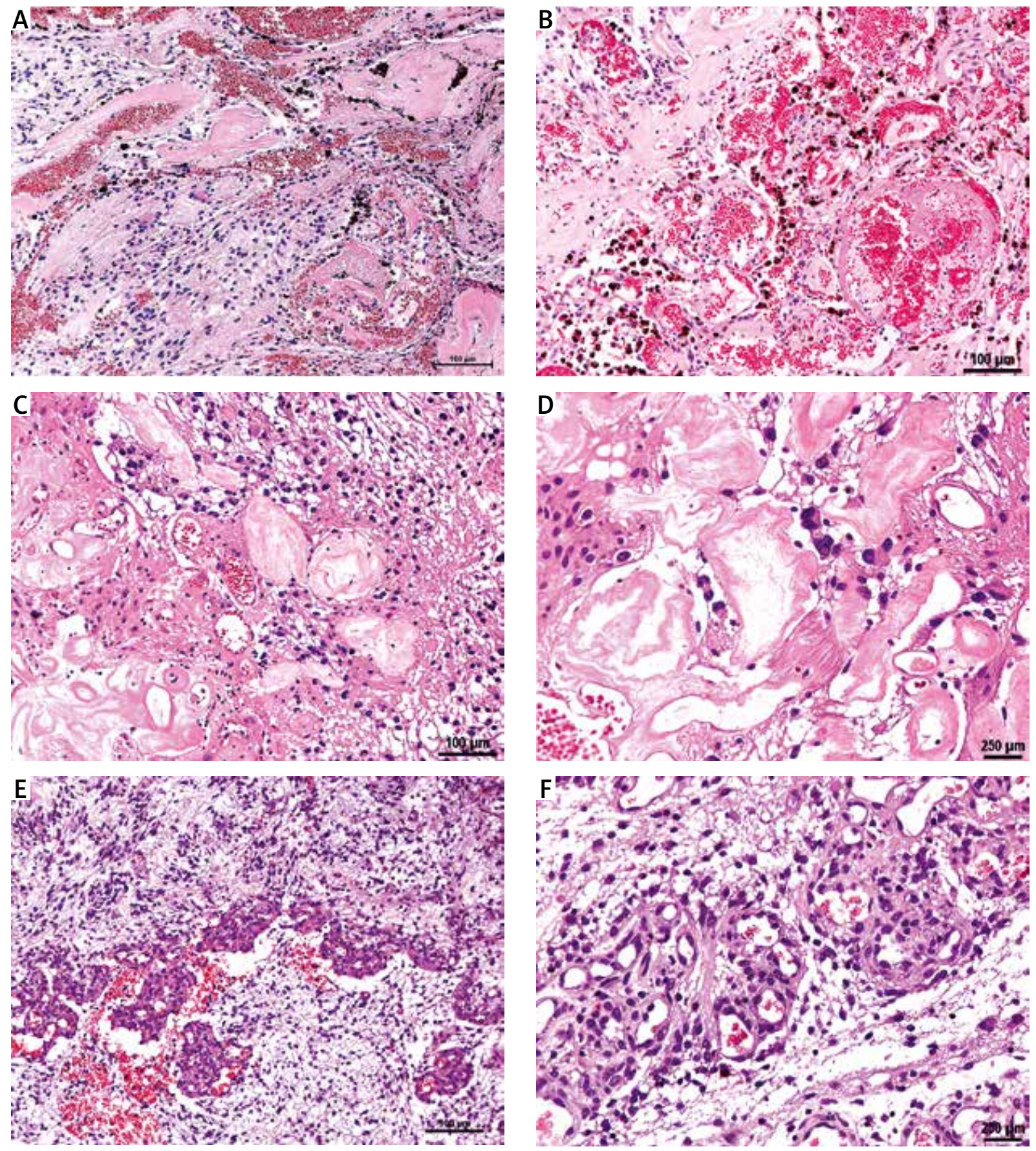

Fig. 5. Vascular changes in pilocytic astrocytomas. A) Neoplastic tissue with advanced vascular abnormalities associated with intratumoural bleeding. B) Conglomerates of hyalinized vessels and hemosiderin deposits. C) Vessels with considerably thickened, fibrous walls. D) Severe vascular hyalinization surrounded by a few neoplastic cells dispersed between conglomerates of vessels. E) Linear arrays of proliferating microvessels. F) Glomeruloid changes of the microvessels with hyperplasia of endothelial cells mimicking high-grade glioma. 

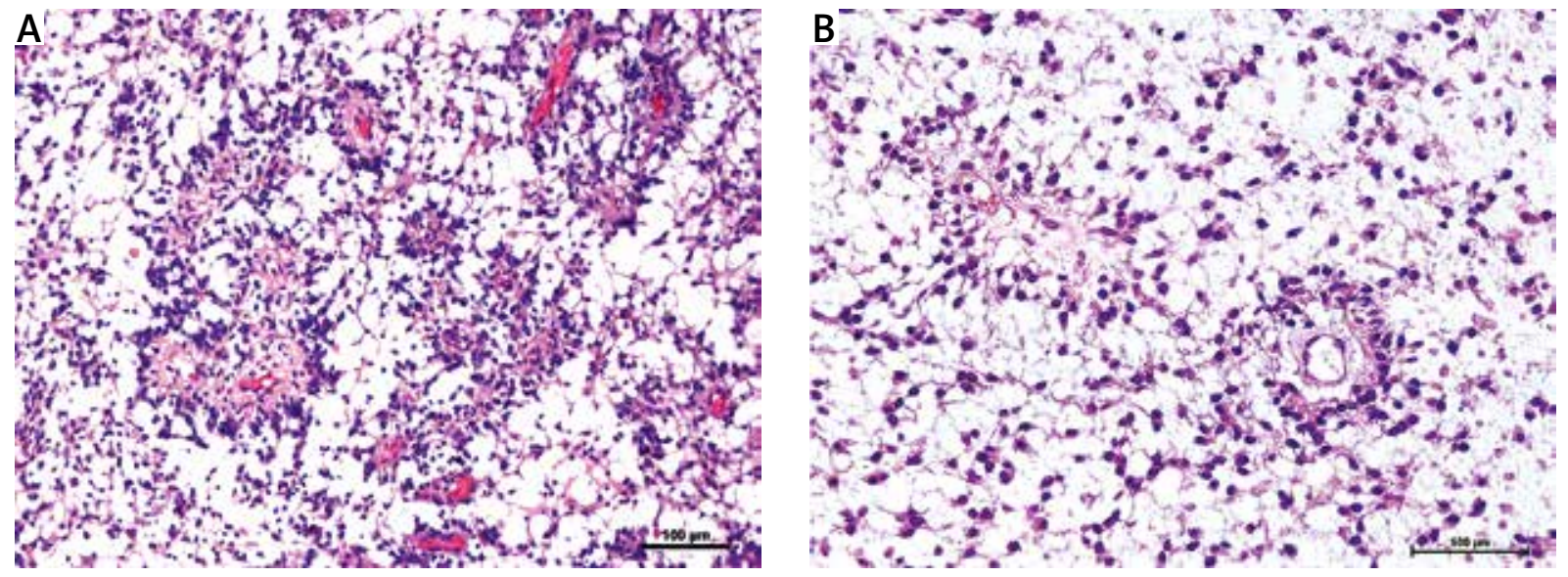

Fig. 6. Pilomyxoid astrocytoma. A) Markedly loose, myxoid background with angiocentric arrangement of neoplastic cells. B) Bipolar tumour cells arranged radially around blood vessels in loose, myxoid tissue.

focally. The Ki-67 proliferative index is usually low, sometimes with a focal increase. Immunohistochemistry for $\mathrm{R} 132 \mathrm{H}$-mutant IDH1 protein is absent in all PAs and helps to distinguish PA from diffuse astrocytomas. Unfortunately, the majority of paediatric diffuse astrocytomas also lack IDH1 and/or IDH2 mutations. Phosphorylated MAPK immunostaining with V600E-mutant BRAF positivity could be detected.

\section{Molecular findings}

There are some genetic alterations that are considered to underlie the development of PAs, with a key role of dysregulation/activation of the mitogen-activated protein kinase (MAPK) pathway, particularly through a tandem duplication leading to an oncogenic BRAF fusion gene $[76,83,102]$. Mitogenactivated protein kinase pathway abnormalities are found in the vast majority of PA cases; thus PA is considered as a one-pathway disease [24]. Recent studies have pointed towards the role of activation of the PI3K/AKT pathway in addition to MAPK/ERK signalling pathways in histologically anaplastic and biologically aggressive PA variants [81].

In sporadic PAs the most common genetic alteration is a tandem duplication at chromosome 7q34, which results in fusion between KIAA1549 and $B R A F$ genes. This tandem duplication is found in $60-94 \%$ of PAs and leads to downstream activation of the MEK/MAPK/ERK/p16 pathway $[12,23,85]$. The KIAA1549-BRAF fusion is more commonly encountered in PAs originating in the cerebellum [40]. These molecular alterations are more frequent in children than in adults [87]. However, their prognostic significance is unclear. KIAA1549-BRAF fusion causes a deletion of the amino-terminal domain of $B R A F$ and constitutive activation of its kinase activity [44]. A proteomic study confirmed the predominance of the MAPK pathway for childhood PA and introduced novel findings regarding ERK-2 expression [6].

The genetic association between neurofibromatosis type 1 and PA is well known. Patients with NF1 demonstrate inactivation of the tumour suppressor gene NF1, which encodes neurofibromin (NF1), a protein involved in the MAPK and mTOR-pathway through RAS-RAF signalling. Loss of neurofibromin leads to an increase of the active form of Ras and negative regulation of the RAS/ERK pathway and activation of the mammalian target of rapamycin mTOR/AKT pathway [21]. The Ras/ERK pathway is also involved in cell differentiation responsible for slow tumour growth. Mechanisms of tumourigenesis in low-grade gliomas with and without NF1 are different, including the different signalling pathways and tumour microenvironment [38].

The molecular changes can be used as diagnostic markers [26]. KIAA1549/BRAF fusion is common in PA but infrequent in diffuse gliomas, whereas IDH1 mutation is common in diffuse astrocytomas in adults and uncommon in PA. Such molecular differences can help to establish the correct diagnosis [51]. Moreover, molecular targeted therapy might be considered as a possible novel therapeutic treatment, particularly in patients suffering from tumours with an unfavourable anatomical location preventing their complete surgical resection. 


\section{Treatment}

Cerebellar and superficial cerebral pilocytic tumours are usually surgically treated by gross total or subtotal resection. Deeply situated lesions can be only partially resected. Disseminated PA lesions are usually treated by multi-modal therapy, including surgical resection, chemotherapy, and radiotherapy with extended-field radiation [16]. It is noteworthy that PAs are generally indolent tumours and attention should be paid to avoiding aggressive therapy [80].

\section{Prognosis}

Pilocytic astrocytomas are typically well-circumscribed, slowly growing WHO grade I lesions that are generally associated with excellent prognosis, favourable long-term outcome or spontaneous regression with a 10 -year survival rate of more than $95 \%$ cases. Total or even subtotal removal is an effective treatment in cerebellar and superficial cerebral pilocytic tumours [29]. The long-term functional outcome is generally favourable, in the absence of post-operative complications and brain stem involvement [2]. The surgery is usually followed by tumour stabilization even when the tumour is only partially resected and the patient does not receive complementary radiation. Deeply located lesions are usually associated with worse prognosis and risk for local recurrence. However, some superficial tumours might also exhibit an unexpected clinical course with recurrences.

Spontaneous involution of PA has been reported in children, particularly in cases associated with NF1 $[19,33,36,56,73,84]$. It has been documented that the optic pathway/hypothalamic gliomas, treated by subtotal resection, biopsy and radiotherapy or radiation alone, might stabilize or even completely disappear on serial MR images [39]. This phenomenon has rarely been observed in adults, especially without NF1 [11]. Nevertheless, postoperative MRI monitoring seems to be important both in adults and in children.

Clinical behaviour is often unpredictable, and PAs may recur locally after incomplete resection or disseminate to the leptomeninges, especially when they are located in the hypothalamic region [1]. It must be noted that recurrences of PA are not associated with histological malignant progression. Some data suggest that PAs in adult patients behave more aggressively than in children and might be associated with recurrences, progression and higher mortal- ity $[31,43,91,94,99]$. The possibility of rapid tumour recurrence and malignant transformation indicate the need for careful post-operative follow-up for adult patients with PAs [30].

Additionally, dissemination into the subarachnoid space occurs in a small percentage of cases, most often related to local recurrences. Dissemination of cerebellar PAs can be associated with obstructive hydrocephalus leading to an unfavourable prognosis [32,41,42]. Leptomeningeal dissemination of the cerebellar tumours into the spinal cord might occur many years after primary surgery $[45,66,78]$; less commonly the meningeal seeding appears at the initial presentation [67]. Spread into the spinal meninges can be observed in PAs of the spinal cord [1,9] and optic chiasm $[4,48]$. Extremely rarely, spinal cord PA can spread via the cerebrospinal fluid pathway (CSF) to the cerebral meninges [69]. Metastases of juvenile PA to the left cerebellar tonsil and lumbosacral region were also reported in PA of the hypothalamic region [70]. Only occasionally, the tumour may exhibit multifocal recurrences and extensive dissemination [7]. An unusual case of recurrent supratentorial intraventricular PA with local recurrence and disseminations along the complete neuraxis in a short period of one year after primary surgery was described [77].

A particular clinicopathological presentation of PAs might be associated with fatal haemorrhages, which are most often subarachnoid (SAH) $[34,46,54$, $61,64]$. Such tumour manifestation is less commonly observed in PMA $[35,89]$. The haemorrhages likely result from vascular abnormalities, often observed in PAs. Tumour haemorrhage should be considered in the differential diagnosis of spontaneous intracerebral haemorrhage [97].

\section{Differential diagnosis}

The correct diagnosis of PA and its differentiation from diffuse gliomas is important as it is related to different prognosis and specific therapy based on the molecular signal pathways. The diagnostic criteria include age of patients, MRI findings, tumour location and typical histology with biphasic picture, presence of piloid cells and degenerative changes with EGBs and Rosenthal fibres. The majority of cases meet these criteria, but some of them present unusual clinicopathological features, including uncommon location, older age group, misleading histological appearance or inadequate biopsy spec- 
imens. Histologically, the diagnosis of PA can often be challenging. The microscopic pictures of PA may mimic some other neoplasms, including pleomorphic xanthoastrocytoma, diffuse astrocytoma and glioblastoma or even piloid reactive gliosis typical for long-standing, non-neoplastic pathological processes. Distinction from all these lesions bears important therapeutic and prognostic implications. Caution is required to avoid misinterpretation; however, in small and/or non-representative biopsy specimens it can be difficult or even impossible. The frequent mutation of $I D H 1$ and $I D H 2$ in diffuse gliomas, which is usually not seen in PAs [51], allows tumours of different prognosis and treatment to be distinguished. Only one case of a 72-year-old woman with a right cerebellar PA of WHO grade I and IDHI mutation has been reported so far [13].

\section{Conclusions}

Pilocytic astrocytoma is a tumour of distinct clinicopathological features, but not infrequently it presents with atypical features, including older age of patients, uncommon location and lack of classic biphasic morphology. The different histopathological pattern, presence of nuclear atypia, vascular changes, mitoses, necrosis and glomeruloid microvascular proliferation can lead to misdiagnosis. Moreover, the biological behaviour of PAs independently of their morphology is not always predictable. In conclusion, the diagnosis of PA may be challenging, and careful analysis of clinical, histopathological and molecular features is required to avoid misinterpretation followed by inadequate therapy.

\section{Disclosure}

Authors report no conflict of interest.

\section{References}

1. Abel TJ, Chowdhary A, Thapa M, Rutledge JC, Geyer JR, Ojemann J, Avellino AM. Spinal cord pilocytic astrocytoma with leptomeningeal dissemination to the brain. Case report and review of the literature. I Neurosurg 2006; 105: 508-514.

2. Ait Khelifa-Gallois N, Laroussinie F, Puget S, Sainte-Rose C, Dellatolas G. Long-term functional outcome of patients with cerebellar pilocytic astrocytoma surgically treated in childhood. Brain Inj 2015; 29: 366-373.

3. Alimohamadi M, Bidabadi MS, Ayan Z, Ketabchi E, Amirjamshidi A. Pilomyxoid astrocytoma with involvement of the sella turcica in an adolescent. J Clin Neurosci 2009; 16: 1648-1649.
4. Alyeldien A, Teuber-Hanselmann S, Cheko A, Holl T, Scholz M, Petridis AK. Diffuse Spinal Leptomeningeal Spread of a Pilocytic Astrocytoma in a 3-year-old Child. Clin Pract 2016; 6: 813.

5. Amato VG, Arienta C, Sparacio F. Dorsally exophytic brain stem tumors: total removal of a medullary pilocytic astrocytoma in child. Clinicopathological considerations and case report. J Neurosurg Sci 1999; 43: 299-304.

6. Anagnostopoulos AK, Dimas KS, Papathanassiou C, Braoudaki M, Anastasiadou E, Vougas K, Karamolegou K, Kontos H, Prodromou N, Tzortzatou-Stathopoulou F, Tsangaris GT. Proteomics studies of childhood pilocytic astrocytoma. J Proteome Res 2011; 10: 2555-2565.

7. Andrychowski J, Taraszewska A, Czernicki Z, Jurkiewicz J, Netczuk T, Dabrowski P. Ten years observation and treatment of multifocal pilocytic astrocytoma. Folia Neuropathol 2009; 47: 362-370.

8. Arantes M, Vaz AR, Honavar M, Resende M, Pereira JR. Pilocytic astrocytoma arising from the pineal gland. J Neuroradiol 2009; 36: 177-178.

9. Arulrajah S, Huisman TA. Pilomyxoid astrocytoma of the spinal cord with cerebrospinal fluid and peritoneal metastasis. Neuropediatrics 2008; 39: 243-245.

10. Azad A, Deb S, Cher L. Primary anaplastic pilocytic astrocytoma. J Clin Neurosci 2009; 16: 1704-1706.

11. Balkhoyor KB, Bernstein M. Involution of diencephalic pilocytic astrocytoma after partial resection. Report of two cases in adults. J Neurosurg 2000; 93: 484-486.

12. Bar EE, Lin A, Tihan T, Burger PC, Eberhart CG. Frequent gains at chromosome $7 q 34$ involving BRAF in pilocytic astrocytoma. J Neuropathol Exp Neurol 2008; 67: 878-887.

13. Behling F, Steinhilber J, Tatagiba M, Bisdas S, Schittenhelm J. IDH1 R132H mutation in a pilocytic astrocytoma: a case report. Int J Clin Exp Pathol 2015; 8: 11809-11813.

14. Bell D, Chitnavis BP, Al-Sarraj S, Connor S, Sharr MM, Gullan RW. Pilocytic astrocytoma of the adult--clinical features, radiological features and management. Br J Neurosurg 2004; 18: 613-616.

15. Berhouma M, Jemel H, Kchir N. Calcified pilocytic astrocytoma of the medulla mimicking a brainstem "stone". Pathologica 2008; 100: 408-410.

16. Bian SX, McAleer MF, Vats TS, Mahajan A, Grosshans DR. Pilocytic astrocytoma with leptomeningeal dissemination. Childs Nerv Syst 2013; 29: 441-450.

17. Brat DJ, Scheithauer BW, Fuller GN, Tihan T. Newly codified glial neoplasms of the 2007 WHO Classification of Tumours of the Central Nervous System: angiocentric glioma, pilomyxoid astrocytoma and pituicytoma. Brain Pathol 2007; 17: 319-324.

18. Brown PD, Anderson SK, Carrero XW, O'Neill BP, Giannini C, Galanis E, Shah SA, Abrams RA, Curran WJ Jr, Buckner JC, Shaw EG. Adult patients with supratentorial pilocytic astrocytoma: long-term follow-up of prospective multicenter clinical trial NCCTG-867251 (Alliance). Neurooncol Pract 2015; 2: 199-204.

19. Brzowski AE, Bazan C 3rd, Mumma JV, Ryan SG. Spontaneous regression of optic glioma in a patient with neurofibromatosis. Neurology 1992; 42: 679-681. 
20. Burkhardt K, Heuberger F, Delavelle J. Pilocytic astrocytoma in the elderly. Clin Neuropathol 2007; 26: 306-310.

21. Chen YH, Gutmann DH. The molecular and cell biology of pediatric low-grade gliomas. Oncogene 2014; 33: 2019-2026.

22. Chourmouzi D, Papadopoulou E, Konstantinidis M, Syrris V, Kouskouras K, Haritanti A, Karkavelas G, Drevelegas A. Manifestations of pilocytic astrocytoma: a pictorial review. Insights Imaging 2014; 5: 387-402.

23. Cin H, Meyer C, Herr R, Janzarik WG, Lambert S, Jones DT, Jacob K, Benner A, Witt H, Remke M, Bender S, Falkenstein F, Van Anh TN, Olbrich H, von Deimling A, Pekrun A, Kulozik AE, Gnekow A, Scheurlen W, Witt O, Omran H, Jabado N, Collins VP, Brummer T, Marschalek R, Lichter P, Korshunov A, Pfister SM. Oncogenic FAM131B-BRAF fusion resulting from 7q34 deletion comprises an alternative mechanism of MAPK pathway activation in pilocytic astrocytoma. Acta Neuropathol 2011; 121 763-774.

24. Collins VP, Jones DT, Giannini C. Pilocytic astrocytoma: pathology, molecular mechanisms and markers. Acta Neuropathol 2015; 129: 775-788.

25. Collins VP TT, VanderBerg SR, Burger PC, Hawkins C. Pilocytic astrocytoma. In: WHO Classification of Tumors of the Central Nervous System. Louis DN, Oghaki H, Wiesttler OD, Cavenee WK, Elison DW (eds.). $4^{\text {th }}$ ed. IARC Press, Lyon 2016; pp. 80-89.

26. Cykowski MD, Allen RA, Kanaly AC, Fung KM, Marshall R, Perry A, Stolzenberg ED, Dunn ST. The differential diagnosis of pilocytic astrocytoma with atypical features and malignant glioma: an analysis of 16 cases with emphasis on distinguishing molecular features. J Neurooncol 2013; 115: 477-486.

27. Cyrine S, Sonia Z, Mounir T, Badderedine S, Kalthoum T, Hedi K Moncef M. Pilocytic astrocytoma: a retrospective study of 32 cases. Clin Neurol Neurosurg 2013; 115: 1220-1225.

28. Daszkiewicz P, Maryniak A, Roszkowski M, Barszcz S. Longterm functional outcome of surgical treatment of juvenile pilocytic astrocytoma of the cerebellum in children. Childs Nerv Syst 2009; 25: 855-860.

29. Dodgshun AJ, Maixner WJ, Hansford JR, Sullivan MJ. Low rates of recurrence and slow progression of pediatric pilocytic astrocytoma after gross-total resection: justification for reducing surveillance imaging. J Neurosurg Pediatr 2016; 17: 569-572.

30. Ellis JA, Waziri A, Balmaceda C, Canoll P, Bruce JN, Sisti MB. Rapid recurrence and malignant transformation of pilocytic astrocytoma in adult patients. J Neurooncol 2009; 95: 377-382.

31. Fiechter M, Hewer E, Knecht U, Wiest R, Beck J, Raabe A, Oertel MF. Adult anaplastic pilocytic astrocytoma - a diagnostic challenge? A case series and literature review. Clin Neurol Neurosurg 2016; 147: 98-104.

32. Figueiredo EG, Matushita H, Machado AG, Plese JP, Rosem berg S, Marino R, Jr. Leptomeningeal dissemination of pilocytic astrocytoma at diagnosis in childhood: two cases report. Arq Neuropsiquiatr 2003; 61: 842-847.

33. Gallucci M, Catalucci A, Scheithauer BW, Forbes GS. Spontaneous involution of pilocytic astrocytoma in a patient without neurofibromatosis type 1: case report. Radiology 2000; 214: 223-226.

34. Garg A, Chugh M, Gaikwad SB, Chandra SP, Gupta V, Mishra NK, Sharma MC. Juvenile pilocytic astrocytoma presenting with subarachnoid hemorrhage. Case report and review of the literature. J Neurosurg 2004; 100: 525-529.

35. Gottfried ON, Fults DW, Townsend JJ, Couldwell WT. Spontaneous hemorrhage associated with a pilomyxoid astrocytoma. Case report. J Neurosurg 2003; 99: 416-420.

36. Gottschalk S, Tavakolian R, Buske A, Tinschert S, Lehmann R. Spontaneous remission of chiasmatic/hypothalamic masses in neurofibromatosis type 1: report of two cases. Neuroradiology 1999; 41: 199-201.

37. Harraher CD, Vogel H, Steinberg GK. Spinal pilocytic astrocytoma in an elderly patient. World Neurosurg 2013; 79: 799 E797-799.

38. Helfferich J, Nijmeijer R, Brouwer OF, Boon M, Fock A, Hoving EW, Meijer L, den Dunnen WF, de Bont ES. Neurofibromatosis type 1 associated low grade gliomas: A comparison with sporadic low grade gliomas. Crit Rev Oncol Hematol 2016; 104: 30-41.

39. Hoffman HJ, Humphreys RP, Drake JM, Rutka JT, Becker LE, Jenkin D, Greenberg M. Optic pathway/hypothalamic gliomas: a dilemma in management. Pediatr Neurosurg 1993; 19: 186-195.

40. Horbinski C, Hamilton RL, Nikiforov Y, Pollack IF. Association of molecular alterations, including BRAF, with biology and outcome in pilocytic astrocytomas. Acta Neuropathol 2010; 119: 641-649.

41. Jamjoom AB, Jamjoom ZA, al-Rayess M. Intraventricular and leptomeningeal dissemination of a pilocytic cerebellar astrocytoma in a child with a ventriculoperitoneal shunt: case report. Br J Neurosurg 1998; 12: 56-58.

42. Jandaghi AB, Bidabadi E, Saadat S, Alijani B, Daliri S, Reyhanian Z, Mashouf M. Leptomeningeal dissemination of pilocytic astrocytoma in a 17-year-old boy. Turk Neurosurg 2014; 24 : 978-981.

43. Johnson DR, Brown PD, Galanis E, Hammack JE. Pilocytic astrocytoma survival in adults: analysis of the Surveillance, Epidemiology, and End Results Program of the National Cancer Institute. J Neurooncol 2012; 108: 187-193.

44. Jones DT, Gronych J, Lichter P, Witt O, Pfister SM. MAPK pathway activation in pilocytic astrocytoma. Cell Mol Life Sci 2012; 69: 1799-1811.

45. Kanda M, Tanaka H, Shinoda S, Masuzawa T. Leptomeningeal dissemination of pilocytic astrocytoma via hematoma in a child. Case report. Neurosurg Focus 2002; 13: ECP2.

46. Kato K, Moteki Y, Nakagawa M, Kadoyama S, Ujiie H. Subarachnoid hemorrhage caused by pilocytic astrocytoma case report. Neurol Med Chir (Tokyo) 51: 82-84.

47. Kim YE, Shin HJ, Suh YL. Pilocytic astrocytoma with extensive psammomatous calcification in the lateral ventricle: a case report. Childs Nerv Syst 2012; 28: 649-652.

48. Kocks W, Kalff R, Reinhardt V, Grote W, Hilke J. Spinal metastasis of pilocytic astrocytoma of the chiasma opticum. Childs Nerv Syst 1989; 5: 118-120.

49. Komotar RJ, Mocco J, Carson BS, Sughrue ME, Zacharia BE, Sisti AC, Canoll PD, Khandji AG, Tihan T, Burger PC, Bruce JN. Pilomyxoid astrocytoma: a review. MedGenMed 2004; 6: 42.

50. Komotar RJ, Mocco J, Jones JE, Zacharia BE, Tihan T, Feldstein NA, Anderson RC. Pilomyxoid astrocytoma: diagnosis, prognosis, and management. Neurosurg Focus 2005; 18: E7. 
51. Korshunov A, Meyer J, Capper D, Christians A, Remke M, Witt H, Pfister S, von Deimling A, Hartmann C. Combined molecular analysis of BRAF and IDH1 distinguishes pilocytic astrocytoma from diffuse astrocytoma. Acta Neuropathol 2009; 118: 401-405.

52. Kumar R, Garg K, Kakkar A, Sharma MC. Giant calcified intraventricular pilocytic astrocytoma: a rare entity. Neurol India 2014; 62: 71-73.

53. Kuroiwa T, Ohta T, Tsutsumi A. Malignant pilocytic astrocytoma in the medulla oblongata: case report. Brain Tumor Pathol 1999; 16: 81-85.

54. Lee CS, Huh JS, Sim KB, Kim YW. Cerebellar pilocytic astrocytoma presenting with intratumor bleeding, subarachnoid hemorrhage, and subdural hematoma. Childs Nerv Syst 2009; 25: $125-128$

55. Lee YY, Van Tassel P, Bruner JM, Moser RP, Share JC. Juvenile pilocytic astrocytomas: CT and MR characteristics. AJR Am J Roentgenol 1989; 152: 1263-1270.

56. Leisti EL, Pyhtinen J, Poyhonen M. Spontaneous decrease of a pilocytic astrocytoma in neurofibromatosis type 1. AJNR Am J Neuroradiol 1996; 17: 1691-1694.

57. Li HM, Hsu SS, Wang JS, Weng MJ, Fu JH, Chen CK, Lai PH. Cerebral pilocytic astrocytoma with spontaneous intracranial hemorrhage in adults. J Chin Med Assoc 2008; 71: 587-593.

58. Listernick R, Ferner RE, Liu GT, Gutmann DH. Optic pathway gliomas in neurofibromatosis-1: controversies and recommendations. Ann Neurol 2007; 61: 189-198.

59. Lyons MK. Pilocytic astrocytoma with spontaneous intracranial hemorrhages in an elderly adult. Clin Neurol Neurosurg 2007; 109: 76-80.

60. Malik A, Deb P, Sharma MC, Sarkar C. Neuropathological spectrum of pilocytic astrocytoma: an Indian series of 120 cases. Pathol Oncol Res 2006; 12: 164-171.

61. Matsumoto K, Akagi K, Abekura M, Maeda Y, Kitagawa M, Ryu jin $\mathrm{H}$, Iwasa N. Hypothalamic pilocytic astrocytoma presenting with intratumoral and subarachnoid hemorrhage. Neurol Med Chir (Tokyo) 1997; 37: 849-851.

62. Matyja E, Grajkowska W, Taraszewska A, Marchel A, Bojarski P, Nauman P. Advanced reactive astrogliosis associated with hemangioblastoma versus astroglial-vascular neoplasm (“angioglioma”). Folia Neuropathol 2007; 45: 120-125.

63. Medress ZA, Xu LW, Ziskin JL, Lefterova MI, Vogel H, Li G. Pilocytic astrocytoma with IDH1 mutation in the cerebellum of an elderly patient. Clin Neuropathol 2015; 34: 96-98.

64. Mesiwala AH, Avellino AM, Roberts TS, Ellenbogen RG. Spontaneous cerebellar hemorrhage due to a juvenile pilocytic astrocytoma: case report and review of the literature. Pediatr Neurosurg 2001; 34: 235-238.

65. Mirone G, Schiabello L, Chibbaro S, Bouazza S, George B. Pediatric primary pilocytic astrocytoma of the cerebellopontine angle: a case report. Childs Nerv Syst 2009; 25: 247-251.

66. Mishima K, Nakamura M, Nakamura H, Nakamura O, Funata N Shitara N. Leptomeningeal dissemination of cerebellar pilocytic astrocytoma. Case report. J Neurosurg 1992; 77: 788-791.

67. Morikawa M, Tamaki N, Kokunai T, Nagashima T, Kurata H, Yamamoto K, Imai Y, Itoh $\mathrm{H}$. Cerebellar pilocytic astrocytoma with leptomeningeal dissemination: case report. Surg Neuro 1997; 48: 49-51; discussion 51-42.
68. Nakano Y, Yamamoto J, Takahashi M, Soejima Y, Akiba D, Kitagawa T, Ueta K, Miyaoka R, Umemura T, Nishizawa S. Pilocytic astrocytoma presenting with atypical features on magnetic resonance imaging. J Neuroradiol 2015; 42: 278-282.

69. Ng HK, Leung CH, Boet R, Poon WS. Spinal cord pilocytic astrocytoma with cranial meningeal metastases. J Clin Neurosci 2001; 8: 374-377.

70. Obana WG, Cogen PH, Davis RL, Edwards MS. Metastatic juvenile pilocytic astrocytoma. Case report. J Neurosurg 1991; 75 : 972-975.

71. Ostrom QT, Gittleman H, Liao P, Rouse C, Chen Y, Dowling J, Wolinsky Y, Kruchko C, Barnholtz-Sloan J. CBTRUS statistical report: primary brain and central nervous system tumors diagnosed in the United States in 2007-2011. Neuro Oncol 2014; 16 Suppl 4: iv1-63.

72. Otero-Rodriguez A, Sarabia-Herrero R, Garcia-Tejeiro M, ZamoraMartinez T. Spontaneous malignant transformation of a supratentorial pilocytic astrocytoma. Neurocirugia (Astur) 2010; 21: 245-252.

73. Parazzini C, Triulzi F, Bianchini E, Agnetti V, Conti M, Zanolini C, Maninetti MM, Rossi LN, Scotti G. Spontaneous involution of optic pathway lesions in neurofibromatosis type 1 : serial contrast MR evaluation. AJNR Am J Neuroradiol 1995; 16: 1711-1718.

74. Pasarikovski CR, Allevato PA, Hammond R, Elashaal AA. Pilocytic astrocytoma of the lower thoracic spine in an adult patient. Acta Neurochir (Wien) 2015; 157: 1179-1181.

75. Peters KB, Cummings TJ, Gururangan S. Transformation of juvenile pilocytic astrocytoma to anaplastic pilocytic astrocytoma in patients with neurofibromatosis type I. J Pediatr Hematol Oncol 2011; 33: e198-201.

76. Pfister S, Janzarik WG, Remke M, Ernst A, Werft W, Becker N, Toedt G, Wittmann A, Kratz C, Olbrich H, Ahmadi R, Thieme B, Joos S, Radlwimmer B, Kulozik A, Pietsch T, Herold-Mende C, Gnekow A, Reifenberger G, Korshunov A, Scheurlen W, Omran H, Lichter P. BRAF gene duplication constitutes a mechanism of MAPK pathway activation in low-grade astrocytomas. J Clin Invest 2008; 118: 1739-1749.

77. Raheja A, Singh PK, Nambirajan A, Sharma MC, Sharma BS. Diffuse leptomeningeal spread of supratentorial recurrent pilocytic astrocytoma in a child. J Pediatr Neurosci 2015; 10: 408-411.

78. Redhu R, Nadkarni TD. Multicompartmental cerebrospinal fluid dissemination of cerebellar pilocytic astrocytoma at presentation. J Clin Neurosci 2011; 18: 1412-1414

79. Reis A, Kuzeyli K, Cobanoglu U, Cakir E, Usul H, Sari A. Pilocytic astrocytoma of neurohypophysis. Neuropathology 2003; 23: 214-218.

80. Reis GF, Tihan T. Therapeutic targets in pilocytic astrocytoma based on genetic analysis. Semin Pediatr Neurol 2015; 22: 23-27.

81. Rodriguez EF, Scheithauer BW, Giannini C, Rynearson A, Cen L, Hoesley B, Gilmer-Flynn H, Sarkaria JN, Jenkins S, Long J, Rodriguez FJ. PI3K/AKT pathway alterations are associated with clinically aggressive and histologically anaplastic subsets of pilocytic astrocytoma. Acta Neuropathol 2011; 121: 407-420. 
82. Rodriguez FJ, Scheithauer BW, Burger PC, Jenkins S, Giannini C. Anaplasia in pilocytic astrocytoma predicts aggressive behavior. Am J Surg Pathol 2010; 34: 147-160.

83. Rodriguez FJ, Ligon AH, Horkayne-Szakaly I, Rushing EJ, Ligon KL, Vena N, Garcia DI, Cameron JD, Eberhart CG. BRAF duplications and MAPK pathway activation are frequent in gliomas of the optic nerve proper. J Neuropathol Exp Neurol 2012; 71: 789-794.

84. Rossi LN, Triulzi F, Parazzini C, Maninetti MM. Spontaneous improvement of optic pathway lesions in children with neurofibromatosis type 1. Neuropediatrics 1999; 30: 205-209.

85. Roth JJ, Santi M, Pollock AN, Harding BN, Rorke-Adams LB, Tooke LS, Biegel JA. Chromosome band 7q34 deletions resulting in KIAA1549-BRAF and FAM131B-BRAF fusions in pediatric low-grade Gliomas. Brain Pathol 2015; 25: 182-192.

86. Saad A, Tuli S, Ali EN, Houtchens M, Delalle I, Kesari S. Pilocytic astrocytoma of the spinal cord in an adult. J Neurooncol 2008; 88: 189-191.

87. Sadighi Z, Slopis J. Pilocytic astrocytoma: a disease with evolving molecular heterogeneity. J Child Neurol 2013; 28: 625-632.

88. Saito K, Toda M, Yoshida K. Pilocytic astrocytoma with anaplastic features presenting good long-term clinical course after surgery alone: a case report. Childs Nerv Syst 2015; 31: 167-171.

89. Shibahara I, Kanamori M, Kumabe T, Endo H, Sonoda Y, Ogawa Y, Watanabe M, Tominaga T. Hemorrhagic onset of pilocytic astrocytoma and pilomyxoid astrocytoma. Brain Tumor Pathol 2009; 26: 1-5.

90. Shibahara I, Kawaguchi T, Kanamori M, Yonezawa S, Takazawa H, Asano K, Ohkuma H, Kaimori M, Sasaki T, Nishijima M. Pilocytic astrocytoma with histological malignant features without previous radiation therapy - case report. Neurol Med Chir (Tokyo) 2011; 51: 144-147.

91. Stuer C, Vilz B, Majores M, Becker A, Schramm J, Simon M. Frequent recurrence and progression in pilocytic astrocytoma in adults. Cancer 2007; 110: 2799-2808.

92. Takada Y, Ohno K, Tamaki M, Hirakawa K. Cerebellopontine angle pilocytic astrocytoma mimicking acoustic schwannoma. Neuroradiology 1999; 41: 949-950.

93. Taraszewska A, Czernicki Z, Andrychowski J. Hemosiderin pigmentation of tumour cells in cerebellar pilocytic astrocytoma associated with post-traumatic hemorrhage in adults. Folia Neuropathol 2005; 43: 172-177.

94. Trabelsi S, Mama N, Ladib M, Popov S, Burford A, Mokni M, Tlili K, Krifa H, Varella-Garcia M, Jones C, Tahar Yacoubi M, Saad A, H'mida Ben Brahim D. Adult recurrent pilocytic astrocytoma: Clinical, histopathological and molecular study. Neurochirurgie 2015; 61: 392-397.

95. Utsuki S, Oka H, Kijima C, Yasui Y, Fujii K, Kawano N. Pilocytic astrocytoma with abundant oligodendroglioma-like component. Brain Tumor Pathol 2012; 29: 103-106.

96. Wade A, Hayhurst C, Amato-Watkins A, Lammie A, Leach P. Cerebellar pilocytic astrocytoma in adults: a management paradigm for a rare tumour. Acta Neurochir (Wien) 2013; 155: 1431-1435.

97. White JB, Piepgras DG, Scheithauer BW, Parisi JE. Rate of spontaneous hemorrhage in histologically proven cases of pilocytic astrocytoma. J Neurosurg 2008; 108: 223-226.
98. Xia J, Yin B, Liu L, Lu Y, Geng D, Tian W. Imaging Features of Pilocytic Astrocytoma in Cerebral Ventricles. Clin Neuroradiol 2015 [Epub ahead of print].

99. Ye JM, Ye MJ, Kranz S, Lo P. A 10 year retrospective study of surgical outcomes of adult intracranial pilocytic astrocytoma. J Clin Neurosci 2014; 21: 2160-2164.

100. Yeo YH, Byrne NP, Counelis GJ, Perry A. Adult with cerebellar anaplastic pilocytic astrocytoma associated with BRAF V600E mutation and p16 loss. Clin Neuropathol 2013; 32: 159-164.

101. Yong EX, McKelvie P, Murphy M, Wang YY. Anaplastic pilocytic astrocytoma. J Clin Neurosci 2014; 21: 1993-1996.

102. Yu J, Deshmukh H, Gutmann RJ, Emnett RJ, Rodriguez FJ, Watson MA, Nagarajan R, Gutmann DH. Alterations of BRAF and HIPK2 loci predominate in sporadic pilocytic astrocytoma. Neurology 2009; 73: 1526-1531.

103. Zhao Y, Feng L, Wei Q, Gao L. Adult cervicomedullary pilocytic astrocytoma: A case report. Experimental and therapeutic medicine 2015; 10: 2221-2223. 